\title{
PSICOANÁLISIS Y MARXISMO: UNA IMPOSIBILIDAD PARADIGMÁTICA
}

\author{
Manuel Martínez*
}

RESUMEN

El presente artículo aborda la polémica y problemática relación entre dos de los grandes edificios teóricos de la modernidad, como lo son el marxismo y el psicoanálisis, los cuales, han sido objeto de numerosos esfuerzos integrativos históricamente hablando. No se trata aquí de pasar revista a tales esfuerzos, si no más bien de comprender conceptualmente sus supuestos de partida y de establecer, en arreglo a estos, la viabilidad de una nueva formulación metateórica.

PALABRAS CLAVES: MARXISMO * PSICOANÁLISIS * FREUDOMARXISMO * SOCIOGÉNESIS * PSICOGÉNESIS

\section{ABSTRACT}

The present article approaches the controversy and problematic relation between two of the great theoreticians of modernity, as they are the marxism and the psychoanalysis, who, have been object of numerous efforts historically speaking.

The purpose is not to review to such efforts, if not rather to include/understand conceptually its departure assumptions and to establish, in adjustment to these, the viability of a new metatheoretic formulation.

KEY WORDS: MARXISM $*$ PSYCHOANALYSIS $*$ FREUDOMARXISM $*$ GENESIS OF THE SOCIETY $*$ PSYCHOGENESIS

\section{MATERIALISMO HISTÓRICO Y SUBJETIVIDAD}

El materialismo histórico parte de la dialéctica entre el sujeto $y$ la naturaleza, la cual se humaniza según las necesidades y posibilidades del primero, haciendo del mundo algo para sí. Las formas de apropiación de la naturaleza no es una cosa que provoca o produce un resultado concreto, sino que es un movimiento que se transforma a sí mismo de manera perpetua y ascendente. Lo específicamente humano es la transformación y apropiación de la realidad en tanto mundo natural y entorno social, estando definida la condición humana por su cualidad

Escuela de Psicología de la Facultad de Ciencias Sociales, Universidad de Costa Rica y Cátedra de Psicología, Universidad Estatal a Distancia. manuelmartinezcr@hotmail.com 
de ser activa y creativa. Cuanto más transforma el ser humano la realidad más y más accede al conocimiento del mundo y de sí mismo (Campos, 1981). En la transformación del mundo la humanidad emerge como tal, autoperpetuándose como especie consciente. Nosológicamente se establece una dialéctica entre el sujeto cognoscente y el objeto de conocimiento, donde a partir de la transformación material se accede a la propia transformación.

Del modo específico como determinada sociedad se apropia de la naturaleza a partir del trabajo, surge la particular conciencia de la realidad que le rodea $y$ de sí, es decir, que la construcción y transformación de la vida social se vehiculiza a través de la forma histórica de trabajo, en tanto hacer propio del acontecer humano (Echeverría, 1986). La transformación de la realidad a partir del trabajo deriva en una cierta organización social para producir, de la cual resultan formas específicas de participación y apropiación material, que corresponderían a determinadas formas de conciencia históricamente definidas. La conciencia obedecerá siempre a intereses de clases contrapuestos, dependiendo de la ostentación o no de los medios de producción, dando como resultado la lucha de clases, que es el factor dinámico y motriz que producirá en cierto momento un nuevo orden del desarrollo de las contradicciones (Marx, 1867). Es sobre la base de esta conceptualización, que se erigirá toda sociología de corte marxista.

Siguiendo a Marx (1848) diremos que la conciencia como tal refleja la organización social que le da sustento y que tiende a reproducir. El grupo social dominante impondrá al conjunto social sus intereses y valores de clase, a partir de los mecanismos de poder institucionales que responden al discurso hegemónico bajo una cobertura de inevitabilidad y universalidad. Empero, la dominación ideológica va más allá de las convenciones y códigos sociales en que se cristaliza, se produce y reproduce en las prácticas sociales, las más de las veces al margen de la conciencia, ergo el individuo se constituye a sí mismo a partir de las experiencias $y$ haceres sociales en una suerte de autodefinición continua históricamente impuesta. Existe también el recurso de la represión por parte de la clase social dominante, en tanto violencia institucionalizada, que encontrará siempre una justificación ideológica.

La alienación de la conciencia, como categoría de análisis del materialismo histórico (Marx, 1844), tiene su máxima expresión en el modo de producción capitalista, donde lo característico es la enajenación absoluta del producto del trabajo. Concomitantemente el conocimiento de la propia realidad es extrañado, deviniendo como falsa conciencia ideológicamente orientada.

Para el marxismo los diferentes modos de producción históricamente hablando crean por sî mismos los gérmenes de su propia destrucción y transformación, clásicamente a partir del capitalismo y como condición de su superación se abre la posibilidad de desarrollo de una conciencia no alienada, sustentada en la libertad, creatividad y capacidad crítica, con una orientación solidaria y valorativa en la asimilación de las relaciones sociales (Campos, 1981).

Los procesos de socialización propiamente dichos se juegan en los niveles diacrónico y sincrónico de la realidad, al nivel diacrónico encontramos un cierto grado de desarrollo histórico-material que define las formas de organización social y la participación de los individuos en la construcción del mundo material. Al nivel sincrónico tenemos las contradicciones inherentes a la organización social y la contribución de los individuos concretos en la conservación o transformación de esta, según sus particulares intereses de clase y adscripciones ideológicas. Estas dimensiones de la vida societal se ubican como totalidad en la experiencia humana.

El sujeto es entonces resultado de una práctica $y$ de una experiencia social, a saber de una praxis que le constituye $y$ a partir de la cual surge la conciencia como construcción simbólica del mundo circundante. La conciencia para el marxismo está mediada por elementos de "verdad" en tanto representación objetiva de la realidad, y por una distorsión ideológicamente inspirada que obtura su comprensión y entendimiento. Teleológicamente, el sujeto es un producto de la historia que le determina y de la cual es también su artífice.

La antropogénesis deviene de una realidad histórica construida sobre la base de las condiciones, tensiones $y$ contradicciones de una materialidad social, que la define desde una perspectiva sociogenética. 
Para el marxismo la característica fundamental del funcionamiento psíquico es la acción-asimilación del contexto social y de las formas de actividad históricamente estructuradas. El individuo se conforma en la interacción directa e indirecta con otros que le hacen sujeto del intercambio y el trato social según sea su participación concreta en la construcción del mundo material.

Los fundamentos teóricos hasta aquí expuestos ubican el contexto donde emergen las individualidades, a la vez que definen los procesos materiales y sociales subyacentes. Empero, arrojan poca luz acerca de los procesos de acción-asimilación diferenciada e individualizada, que es en definitiva lo que constituye la subjetividad.

\section{EL SUJETO DE LA HISTORIA \\ Y EL SUJETO PSICOANALÍTICO}

La psiquis en tanto patrimonio individual debe su existencia a procesos inter-psicológicos, es decir sociales, $y$ es a partir de esta psicología social de la personalidad que se explican ciertos rasgos significativos incorporados al sujeto, tales como: adscripción de clase, ideología dominante $y$ visión del mundo en general que dan cuenta en parte del acontecer psicológico. Sin embargo, prácticamente se obvian los procesos endo e intrapsíquico de asimilación e interiorización de los contextos históricos-culturales concretos. Se obvia también la génesis y organización de los procesos psíquicos que conforman la particular estructura de la personalidad en un sentido filo $y$ ontogenético.

La experiencia humana integra, pero a la vez va más allá de las condiciones materiales de existencia y de las ideologías que le subyacen, realizándose una subjetivación individualizada del contexto histórico-social (Martín-Baró, 1985); dichas experiencias y procesos psíquicos inéditos trascienden la concepción de sujeto histórico que caracteriza al marxismo. En este estado de cosas los esfuerzos por establecer una psicología profunda o abismal como la denominara Freud, encuentra su límite y explicación última en el sujeto de la historia y en la materialidad social que le caracteriza; cualquier sociología de la personalidad queda a mitad de camino entre la sociedad y el individuo.

Los esfuerzos históricamente emprendidos para conciliar y articular los monumentales edificios teóricos del marxismo y el psicoanálisis, han sido diversos y polémicos, pasan por asimilar la noción de pulsión en arreglo a la concepción económica marxista, siendo un conspicuo representante de esta tendencia Wilhelm Reich, hasta la introducción de la lucha de clases en la conformación de la personalidad en el psicoanálisis, son célebres y ampliamente conocidos los esfuerzos en tal sentido de Erich Fromm. Estos $y$ otros muchos intentos, cuya reseña $y$ detalle excederían los propósitos del presente texto, quedan en deuda con las teorías tributarias al desvirtuarlas, debido en parte a una imposibilidad epistemológica, óntica y metódica de tender puentes entre tales saberes; de lo que se concluye que sus aportaciones han sido en general poco relevantes.

La libido no puede ser la fuerza motriz de la historia - en el sentido que lo entiende el marxismo, que orienta la transformación del entorno material. Por otra parte, las determinaciones histórico-sociales tienen tan sólo un peso relativo en la constitución de la subjetividad para el psicoanálisis, el cual brinda clara preponderancia a los fenómenos de lo inconsciente. La evolución psíquica del individuo que es analíticamente entendida a partir del tránsito de la libido por distintas etapas filogenéticamente establecidas de su desarrollo y de los complejos correspondientes, no es mutuamente asimilable al sujeto como concreción histórico-social que encuentra su explicación primera en las condiciones materiales de existencia históricamente dadas. El sujeto de la historia no se corresponde al sujeto del inconsciente $y$ viceversa, todo parece indicar que estamos en presencia de dos órdenes en la constitución del sujeto disímiles pero quizá complementarias, no a partir de una hipotética conjunción, sino a partir de sus límites y alcances comprensivos. La "sociología freudiana" se encuentra indefectiblemente atada al individuo, en tanto la "psicología marxista" apenas franqueaba el umbral de la sociedad.

Freud (1929) establece una relación onto $y$ filogenética entre el periodo del animismo que caracterizó el pensamiento especulativo de 
la especie humana en sus albores, $y$ el correspondiente proceso psíquico característico de la etapa pre-edípica denominado omnipotencia del pensamiento. En la vida adulta va a reconocer reminiscencias de este "pensamiento mágico" en la cotidianidad, la superstición y fundamentalmente en la religión. Análogamente establece un correlato entre el padre de la horda primordial amado y temido con el padre edípico a quien se venera, envidia y teme. Al igual que ocurre con las religiones pastorales una vez que el padre de la infancia cae en falta, la omnisciencia y omnipotencia se transfieren a Dios Padre, en quien se depositan a la vez funciones de protección, recompensa y castigo propias del padre.

Tal y como lo plantea Erick Fromm (1973), para Freud la unidad social primordial es la familia y particularmente el denominado sistema parental, es en el seno de la familia donde se constituye la base y cimientos de la subjetividad y el asiento de la estructura caracterial básica, fundante $y$ determinante en la vida psíquica del individuo; lo cual acaece en los primeros años de la vida hasta la resolución edípica. En la circunscripción familiar emergen no sólo los rasgos de carácter, sino que es el lugar donde se constituye el psiquismo mismo del individuo a partir de las represiones pulsionales, su manto $y$ destino, la modalidad específica de resolución edípica y la emergencia del super yo en tanto conciencia moral y prescripción cultural. A la experiencia familiar primordial obedece también la elección de los mecanismos defensivos, los modelajes e identificaciones - sexuales y psicológicas- y la asunción de las pautas sociales. El individuo se socializa y constituye en el espacio familiar, a partir de ciertas cogniciones, certidumbres $y$ afectividades.

Si bien es cierto el individuo encuentra su anclaje en el intersticio familiar, para Freud la familia aparece como una realidad ahistórica y socialmente descontextuada y aislada; es una realidad y un fin en sí mismo. Freud desdeña los determinismos históricos y sociales que atraviesan las familias y no imbrica los grupos familiares en ámbitos sociales mayores, de los cuales necesariamente las familias son parte constitutiva, derivando de dichos contextos rasgos esenciales de su fisonomía y naturaleza.

\section{FREUD Y EL MARXISMO}

Freud (1932) reconoce explícita ignorancia del marxismo, empero ello no le inhibe dirigir algunas observaciones críticas a la concepción marxista del mundo; se pronuncia al respecto impelido por la vigencia social del marxismo, ya que en su tiempo el "fantasma" no sólo recorría Europa sino también Asia, América y el mundo entero. Las pocas observaciones de Freud respecto al marxismo, generales y tangenciales como fueron, se dieron más por obligación sustentada en las críticas que desde el marxismo se endilgaban al psicoanálisis $y$ en la necesidad de limpiar la casa de ciertos esfuerzos especulativos para lograr alguna suerte de integración metateórica de ambos sistemas, y sin lugar a dudas, debido a que vio un formidable adversario a sus propias concepciones. Las críticas freudianas al marxismo se pueden sintetizar de la siguiente manera (Freud, 1932):

1. Para Freud el hecho que la evolución de las formas sociales - seguramente está hablando de los modos de producción- estén históricamente predeterminados, no es otra cosa más que reminiscencias de la dialéctica idealista hegeliana, $y$ nunca una postura materialista.

2. La evolución social para Freud no está determinada por la lucha de clases, sino por el natural impulso agresivo de los seres humanos en combinación con el desarrollo de los medios de destrucción, lo que acaece como constante histórica es la dialéctica de los vencedores $y$ vencidos y el cambio de amo.

3. A pesar de que reconoce que las condiciones económicas ejercen un poderoso influjo sobre las disposiciones intelectuales, éticas y artísticas, niega que sean los únicos determinantes del comportamiento social y piensa que no explican en definitiva la diversidad social.

4. Freud critica al marxismo por prescindir de los factores psicológicos que a su juicio contribuyen al establecimiento de los diferentes regímenes sociales en un sentido de causalidad.

5. Freud hace una táctica división, que no es consistente con el marxismo, entre la sociedad como tal y la cultura en tanto reservorio de las tradiciones, aliada del súper-yo y reticente al cambio. 
6. Según Freud, la transformación social no es un acto deliberado y conciente, es más bien hijo de una evolución que no se precipita e impone. Duda que el "nuevo hombre" surja de las ruinas del viejo régimen por artilugio del cambio del sistema social.

7. Freud acusa al marxismo por su conspicua reticencia a toda crítica y revisión, que lo condena al orden doctrinal y al inmovilismo e intolerancia que ello supone.

8. Freud cree que existe una inspiración mesiánica en el marxismo de un más allá mejor, que al igual que las religiones mueve a sus creyentes, con la única diferencia de que el paraíso será establecido en la tierra.

A continuación algunas reacciones en relación con las observaciones críticas freudianas en torno al marxismo.

En relación con la observación de las reminiscencias idealistas hegelianas en la dialéctica histórica de los modos de producción y particularmente en este punto, Freud hace acopio de su confesa ignorancia del marxismo, ya que la sucesión dialéctica e histórica de los modos de producción no fue un artilugio o impostura teórica o filosófica, sino que está sustentada y justificada en un exhaustivo y riguroso análisis de la historia. Quizá el problema estriba en que Freud no cree en la existencia de leyes que gobiernen el cosmos social y a partir de las cuales se puedan establecer algunas regularidades que permitan pronosticar el movimiento social como tal. Sin embargo, sus propios constructos son hijos de una acuciosa observación clínica que le permite formular su noción de aparato psíquico, de las instancias psíquicas y del comercio existente entre ellas; lo cual en su sistema teórico tienen un rango de axiomático que sustenta en buena parte el edificio teórico freudiano. La crítica de Freud no tiene mayor desarrollo ni asidero en tal sentido.

La negación freudiana de la lucha de clases es un punto crítico a cualquier esfuerzo de asimilación e integración entre el marxismo $y$ el psicoanálisis, al ser precisamente la lucha de clases el motor del desarrollo histórico y estar en la base de toda estructura social y económica en una condición fundante $y$ determinante para el marxismo. De hecho políticamente su aceptación es punto de fractura entre marxistas y socialdemócratas de todo tipo y género, de lo cual derivan las sustanciales divergencias programáticas, tácticas y estratégicas. Donde Marx (1848) ve lucha de clases, Freud (1921) ve un primordial instinto de destrucción y muerte, cuya manifestación agresiva se da en arreglo a los medios de destrucción históricamente dados, en última instancia el modo de participación de los individuos concretos en la organización social dependerá básicamente de su particular estructuración psíquica, esto es, de sus anhelos, deseos, represiones, complejos, mecanismos defensivos y mandatos superyoicos, más allá de las clases sociales. Freud no se preocupó ni estableció diferenciación en la constitución de la psiquis en función de las clases sociales, etnias o nacionalidades, antes bien establece la existencia de idénticos procesos psíquicos entre los individuos y su diferenciación está más determinada por aspectos vinculares $y$ afectivos parentales $y$ familiares, que por la condición social propiamente dicha.

Freud parte del individuo como unidad de análisis y a pesar de reconocer la influencia societal, su interrogación fundamentalmente se dirige a la individualidad como tal, a aquellos elementos, procesos y eventos que nos constituyen en nuestra particular y única forma de ser, que para Freud tendrá su explicación última en vivencias endo e intrapsíquicas. A diferencia de Freud el sujeto en Marx es social y es justamente el entramado social e histórico el que explica y define las subjetividades, enunciadas así, en plural. La ontogénesis marxista no es asimilable al sujeto óntico del psicoanálisis, de allí la imposibilidad epistémica y ecléctica de conjugar estos dos sistemas conceptuales.

Para Freud (1915) el origen del movimiento social es el individuo y específicamente las mociones pulsionales que la cultura va a domesticar, el fin de la cultura es precisamente trocar las mociones pulsionales hacia fines $y$ destinos socialmente aceptados, coartando en este acto a través de diversos mecanismos psíquicos aquellas tendencias primigenias que se oponen a la acción civilizatoria, convirtiéndolas en pulsión sublimada. La concepción marxista dicta que lo que el ser humano debe gobernar no es la naturaleza interna, sino el mundo circundante 
en tanto exterioridad, es precisamente a partir de este cometido que los seres humanos se "organizan" para humanizar la realidad, $y$ es este fin social el que va a determinar la naturaleza de las relaciones sociales, $y$ las formas de conciencia históricamente dadas. Existe un origen y un fin último que parten desde $y$ hacia lugares diferentes, derivando explicaciones disímiles del ser humano, que en un caso está construido a partir de las relaciones sociales que se internalizan y en el otro, a partir de una economía pulsional que encuentra, sólo en parte, su acicate en la acción cultural. Dicho de una manera esquemática el individuo es para el marxismo un producto social, en tanto para el psicoanálisis el individuo es el resultado de tendencias y experiencias psíquicas primigenias mediadas - hasta cierto punto- por las restricciones civilizatorias.

La noción de cultura en Freud no es asimilable a la concepción de sociedad en Marx, en tanto que para este último el devenir social es el resultado de leyes del desarrollo histórico en una creciente complejización y en cuyo seno se encuentra el germen de la propia destrucción y el advenimiento dialéctico de un nuevo orden; para Freud, la cultura tiene su asiento en un pacto mítico primordial para gobernar una suerte de salvajismo original opuesto a la civilización, necesario para la sobrevivencia de la especie, esta es la función esencial que caracteriza a la cultura como tal.

Freud se preocupa poco de las formas históricas en que tales procesos acontecen, siendo la cultura la responsable de la transmisión de la tradición, es aliada del superyo y reticente al cambio social, que significa necesariamente replanteamientos paradigmáticos y morales. Los cambios sociales no trastocan la función de la cultura, existe en Freud una especie de inmovilismo histórico que lo descoloca absolutamente del marxismo, al punto que las vicisitudes de la historia, son tan sólo modalidades para cumplir una única y estricta función, cual es la represión pulsional. Desde el punto de vista de la construcción del psiquismo individual, ¿acaso existe otro para Freud?, la diversidad de modismos sociales y culturales van a tener como única consecuencia una mayor o menor represión libidinal.

Básicamente para Freud el ser humano después del pacto primordial en los albores de los tiempos, el griego clásico, el hombre del medioevo, el moderno y el posmoderno, son esencialmente semejantes en cuanto que sufren los mismos dilemas, complejos y conflictos, a partir de una estructura y funcionamiento psíquico que se mantiene, incólumes desafiando el tiempo y la historia. Lo histórico-social es tan sólo el telón del fondo donde se desenvuelve esta dramaturgia sempiterna. Freud no hace diferenciación, como sí lo hace Marx, entre el mundo antiguo, el medieval, el capitalismo y el socialismo; tampoco lo hace entre el amo y el esclavo, el siervo y el señor o el obrero y el capitalista; estas categorías de análisis, piedra angular en el marxismo son desdeñadas por Freud. Duda también que exista la posibilidad de una construcción conciente y prescrita del orden social y consecuentemente duda que del cambio en el modo de producción capitalista surja el nuevo hombre, tal y como lo anuncia el marxismo. No podía ser de otra manera, ya que el ser humano preso de sus deseos y complejos, es y será esencialmente, siempre el mismo.

La acusación freudiana al marxismo de ser refractario a la crítica y a la revisión, sólo podría sostenerse desde el desconocimiento de Freud del pensamiento de Marx y de su evolución ulterior, incluso en su propio tiempo. Acaso estaba pensando en el marxismo-leninismo o en su variante estalinista, en todo caso desconoce al marxismo como corpus teórico policémico y polémico en sí mismo, con profundas y desgarradoras luchas intestinas, tal y como aconteció con el psicoanálisis en vida y después de la muerte de Freud.

En cuanto a la inspiración mesiánica que habla Freud en relación con el marxismo, encuentra su correlato en El porvenir de una ilusión (Freud, 1927), donde se apuesta sin ambajes un desarrollo cultural con un mayor predominio de la racionalidad sobre la vida afectiva, en tanto momento culminante de la evolución humana ¿existe aquí una suerte de inspiración o utopía psíquica?

\section{SÍNTESIS}

Para el marxismo, el sujeto deviene como tal en la transformación de la naturaleza y del 
mundo circundante a partir de la construcción de una materialidad que le define. La construcción material del mundo es siempre social, cualidad que desde su génesis incorpora y constituye al sujeto. El sujeto del psicoanálisis, por su parte, se concibe en su estado original como un ser anónimo, carente y deseante, cuya naturaleza primigenia — que va dominar - le impulsa a la satisfacción de las propias necesidades a despecho y en detrimento de la de los demás. Freud (1912) entra aquí en una situación dilemática, ya que, tal y como él mismo lo reconoce, un estado semejante de cosas sólo anticipa la aniquilación del género humano, de allí la necesidad de la denegación por parte del sujeto de los propios deseos primordiales, como condición para vivir en sociedad $y$ perpetuarse como especie.

Para el marxismo el individuo no preexiste a la sociedad, en tanto para el psicoanálisis existe un individuo mítico, previo a la negación de su deseo y a toda forma de organización social. Dicho de otra manera, el dominio pulsional impone rendimientos y tareas de naturaleza psíquica diferentes al dominio sobre el mundo material. El sujeto del inconsciente no es homologable al sujeto de la historia, el sujeto del marxismo es producto de una materialidad social, en tanto el sujeto del psicoanálisis es el resultado del gobierno pulsional.

Desde el punto de vista marxista el sujeto es el producto de una práctica y experiencia social, siendo la característica fundamental del psiquismo la acción-asimilación de las diversas formas de actividad históricamente estructuradas. La antropogénesis tiene su origen en una realidad histórico-social que la define en una perspectiva sociogenética. Ahora bien, la acciónasimilación individualizada, base de toda subjetividad, es un punto ciego en la óptica marxista. El materialismo histórico no tiene una noción de aparato psíquico a partir del cual se organizan, regulan y explican los procesos psicológicos $y$ las diferencias individuales, piedra angular de toda psicología comprensiva. Sin embargo, es importante tener presente que el materialismo histórico surge como una explicación de la historia $y$ no del individuo $y$ su circunstancialidad particular, por tanto, sería injusto cobrarle la ausencia de una concepción más o menos acabada del psiquismo humano.
Es necesario indicar que a lo largo de la historia se han hecho ingentes esfuerzos por construir una psicología de base materialista, que inspirada en el materialismo histórico dé cuenta de la subjetividad y sus avatares. Estos esfuerzos integrativos son múltiples y disímiles, parten de una pretendida psicología soviética de orientación fisiológica más próxima al positivismo que al materialismo histórico, hasta el riguroso enfoque histórico-cultural con un confeso $y$ a veces no bien comprendido afán integrador. Sin embargo, la reseña de tales esfuerzos sería materia para otro trabajo.

Para el materialismo histórico una cualidad esencial del psiquismo humano lo constituye la conciencia, la cual no es una característica o función dada, sino que es el resultado de un largo proceso de evolución (Engels, 1876), entendida no exclusivamente en un sentido biológico, si no ante todo en una dimensión histórica. La conciencia surge de una praxis como construcción simbólica del mundo circundante, por tanto, la conciencia es un "reflejo activo" de la organización social que le da sustento y que a la vez tiende a reproducir. La conciencia como tal contiene elementos de verdad en tanto representación/recreación de la realidad, a la vez que una distorsión ideológicamente inspirada, que obtura la comprensión y entendimiento de esta. La conciencia tiende a reproducir el discurso hegemónico, estando ideológicamente orientada al servicio de los grupos dominantes. Por tanto, dentro de esta concepción toda Psicología debe ser por definición liberadora $y$ debe tener como objetivo la superación de la falsa conciencia y el establecimiento de una práctica transformadora de aquellos factores que contribuyen a la enajenación de la conciencia.

Dentro de la topología psíquica freudiana lo inconsciente es la cualidad básica y esencial que caracteriza al aparato psíquico, de hecho, es lo común a las distintas instancias psíquicas. Por otra parte, para Freud (1938), lo conciente es efímero y no reside en él la motivación y explicación última del comportamiento, cuya naturaleza es claramente inconsciente.

La divergencia, en relación con el lugar y función de la conciencia entre el marxismo y el psicoanálisis no es simplemente un asunto de énfasis, $y$ menos la preponderancia de lo inconsciente en 
el psicoanálisis y su ausencia dentro del modelo conceptual marxista. De esta diferencia se derivan divergencias epistémicas, ónticas y heurísticas que no pueden soslayarse a la hora de cualquier esfuerzo integrativo meta-teórico.

La unidad social básica de análisis al nivel psicoanálitico es el conglomerado familiar, asumido desde una perspectiva ahistórica. Lo social apenas si se vislumbra en mandatos y exigencias parentales, de cuya génesis Freud acusa una absoluta despreocupación. La propia noción de cultura en Freud es ahistórica y sirve esencialmente a fines $y$ propósitos endopsíquicos onto y filogenéticamente hablando. El orden social como tal, su análisis y estudio no es una prioridad para Freud, antes bien, lo social deriva del orden individual en cuanto a su origen y desarrollo. Freud se mantiene también indiferente en relación con la estructuración social históricamente dada. La determinación del sujeto se encuentra más allá y más acá del orden social.

En Freud, la participación social de los individuos no dependerá de su condición de clase, sino de motivaciones psicógenas básicamente de naturaleza inconsciente $y$ con un claro origen vincular y afectivo. Por otra parte, la lucha de clases piedra angular del marxismo, no se puede reducir jamás, como alguna vez se pretendió, al eros y tánatos freudiano, ya que supera el oscuro origen biológico pulsional que caracteriza a dichas concepciones, a partir justamente de la clara dimensión social en que se inspira el concepto de lucha de clases.

La comprensión social y del individuo no se agotan en el análisis estructural, histórico, semiótico ni del inconsciente, las cuales devienen como dimensiones heterónomas de la realidad. Quizá ha llegado la hora de renunciar a afanes omnicomprensivos y omniexplicativos que den cuenta de la totalidad del acontecer humano, $y$ mirar con absoluto respeto otros desarrollos teoréticos cuyas discursividades vayan más allá del propio, reconociendo implícitamente nuestras limitaciones.

\section{BIBLIOGRAFÍA}

Campos, Armando. Hacia una teoría psicológica de la alienación. San José. csuCA. 1981.
• ¿Qué es la Psicología del Trabajo? San José. csuCA. 1981.

Marx, Karl y Engels, Friedrich. 1848. Manifiesto del Partido Comunista. Madrid. Biblioteca Nueva. 2000.

Engels, Friedrich. 1876. "El papel del trabajo en la transformación del mono en hombre". En Karl Marx y Friedrich Engels. Obras Escogidas. Moscú. Editorial Progreso. 1976.

Echeverría, Priscilla. "Trabajo y socia-lización penitenciaria”. San José. Tesis de grado Universidad de Costa Rica. 1986.

Freud, Sigmund. 1929. "El malestar en la cultura". Obras Completas Tomo II. Madrid. Editorial Nueva Biblioteca. 1996.

1932. "Nuevas lecciones introductorias al psicoanálisis". Obras Completas Tomo III. Madrid. Editorial Nueva Biblioteca. 1996.

. 1921. "Psicología de las masas y análisis del yo". Obras completas Tomo III. Madrid. Editorial Nueva Biblioteca. 1996.

. 1912. "Tótem y Tabú". Obras Completas Tomo II. Madrid. Editorial Nueva Biblioteca. 1996.

. 1938. "Compendio de psicoanálisis". Obras Completas Tomo III. Madrid. Editorial Nueva Biblioteca. 1996.

. 1927. "Compendio de Psicoanálisis". Obras Completas Tomo III. Madrid. Editorial Nueva Biblioteca. 1996.

Fromm, Erich. Sociopsicoanálisis del contemporáneo mexicano. México. Fondo de Cultura Económica. 1973.

Martín-Baró, Ignacio. "Entre el individuo $y$ la sociedad". En: Acción e 
ideología. Psicología Social desde Centroamérica. San Salvador. UCA Editores. 1985.

Marx, Karl. 1844. Manuscritos económicos filosóficos. Madrid. Alianza. 1984.
1867. El capital. México. Siglo Veintiuno. 1987.

Marx, Karl y Engels, Friedrich. 1846. La ideología Alemana. San José. Nueva Década. 1985. 
